\title{
CNC MILLING MACHINE PRECISION ANALYSIS THROUGH NUMERICAL MODELLING
}

\author{
Jozef Svetlík' ${ }^{1}$ Peter Demeč ${ }^{1}$, Ján Král ${ }^{n}$ \\ 1 Technical University of Košice, Faculty of Mechanical Engineering, Letná 9, 04200 Košice, Slovak Republic, \\ e-mail: jozef.svetlik@tuke.sk, peter.demec@tuke.sk, kral.jan@tuke.sk
}

Received: 2017.03 .30

Accepted: 2017.05.07

Published: 2017.06.01

\begin{abstract}
The motive behind the effort to make virtual prototyping more sophisticated is first of all cost reduction of manufacturing machine design, followed by reduction of lead time for development, prototyping and testing of the pre-manufacturing machine series. This article deals with the analysis of manufacturing precision of a 3-axial, numerically controlled milling machine. The methodology for precision analysis rests on a selected simplified numerical calculation model of a manufacturing machine on which virtual machining has been conducted. The mechanical inaccuracy itself is calculated by computer via the FEM analysis. The results are processed for visualization by the Excel software.
\end{abstract}

Keywords: accuracy of manufacturing machine, virtual prototyping, modal analysis, virtual model.

\section{INTRODUCTION}

In order to analytically examine the precision of machining performed by any particular machine on a particular workpiece/part, the said machine tool must be replaced by an appropriate mathematical model. As a rule, the ideal case would have as simple a model as possible, where the model must also comply with the key facts and properties affecting the working precision $[8 \div 13,19]$.

Upon examining the working precision of the machine tool in our analysis, making use of the respective mathematical models, it is necessary to set an equation describing the tool's trajectory and plot it in the same system of coordinates as describes the workpiece/part and to establish the effects influencing inaccuracies bound to individual nodes of particular machine tools and their impact on the total precision of the machining. Finally, these effects must be applied to the point the tool meets the workpiece/part and it is here they need to be superimposed [1]
Such analysis should be approached in the outlined steps, as needed:

- to establish the sequence of nodes in the machine tool - model bodies (both motile and immotile) in direction from the workpiece/part to the tool,

- to establish systems of coordinates for model bodies subject to calculation model of the machine tool,

- to define mathematically the mutual end positions of the model bodies subject to the calculation model of the machine tool - column vectors $\left\{\mathrm{K}_{\mathrm{i}+1, \mathrm{i}}\right\}$,

- to define mathematically the motions of specific model bodies subject to calculation model of the machine tool,

- to define mathematically transformational vectors of straight line motions $\left\{\mathrm{T}_{\mathrm{i}+1, \mathrm{i}}(\mathrm{t})\right\}$ and transformational matrices of rotary motions $\left[\mathrm{R}_{\mathrm{i}+1, \mathrm{i}}(\mathrm{t})\right]$ of specific model bodies subject to calculation model of the machining center,

- to define mathematically inaccuracies and deformities of individual model bodies subject to calculation model of the machining center and their time changes in course of machining [1]. 
When creating a calculation model of a machine tool subject to our precision analysis, we draw on design composition of its support system. Therefore we can contend with replacing individual nodes of the machine tool support system with bodies of a simplified shape. Nevertheless, their properties with respect to the original nodes remain intact.

Machine tool precision is a property of the machine tool enabling it to manufacture parts of prescribed forms and dimensions within the required tolerance limits and with the required surface quality of the machined area. The requirements placed on the machine tool arise from the precision of parts manufactured by a particular machine. Those requirements are precisely defined in manufacturing drawings together with the respective tolerance limits and must be adhered to. Equally important is to pay attention to the roughness of the surfaces where it holds that the more precise the machine is to be, the less rough the surfaces (clamping surface, sliding surface, free surface...) it produces are allowed [2].

Geometrical precision (static) - is defined by the STS 200300 standard, compliant with the ISO standards. The $200301-200389$ standards prescribe established values of variances in the geometrical and working precision of particular machines and conditions for establishing geometrical precision for specific machines [3].

Working precision (dynamic) - is defined by the STN 200390 standard. The geometrical precision does not account for the effects of a load of cutting forces and resistances on the machine $[3,16]$.
Kinematic and positioning precision - a positioning precision checkup has been introduced to $\mathrm{NC}$ and $\mathrm{CNC}$ machine tools, measuring the variance the real position of the motile part displays in comparison to the position programmed for this part. The precision of a specific axis achieved by a numerically controlled machine may be expressed through three parameters $[3,18]$ :

- precision of repeated startup $\mathrm{R}$,

- maximum numbness $\mathrm{N}$,

- maximum position variance M.

Precision over time - expresses the stability of the working precision of the machine tool throughout its lifetime. Since no effective standards exist for this type of precision, it is evaluated according to mass statistical data on the precision of components manufactured by the specific machine [2].

\section{DEFINING THE OBJECT SUBJECTED TO MATHEMATICAL MODELING}

The object selected for modeling is a simple, and in practical terms most frequently occurring 3-axial milling machine, with a vertical machining axis designed in the so-called gantry alignment (Fig. 1). The milling machine consists of the following bodies:

- $\mathrm{T}_{1}$ - bed,

- $\mathrm{T}_{2}$-transom,

- $\mathrm{T}_{3}$ - support,

- $\mathrm{T}_{4}$ - slide with a screw drive,

- $\mathrm{T}_{5}$ - spindle.

Selection of the milling machine was based on the platform of a specific LMG2A-CB6-CC8

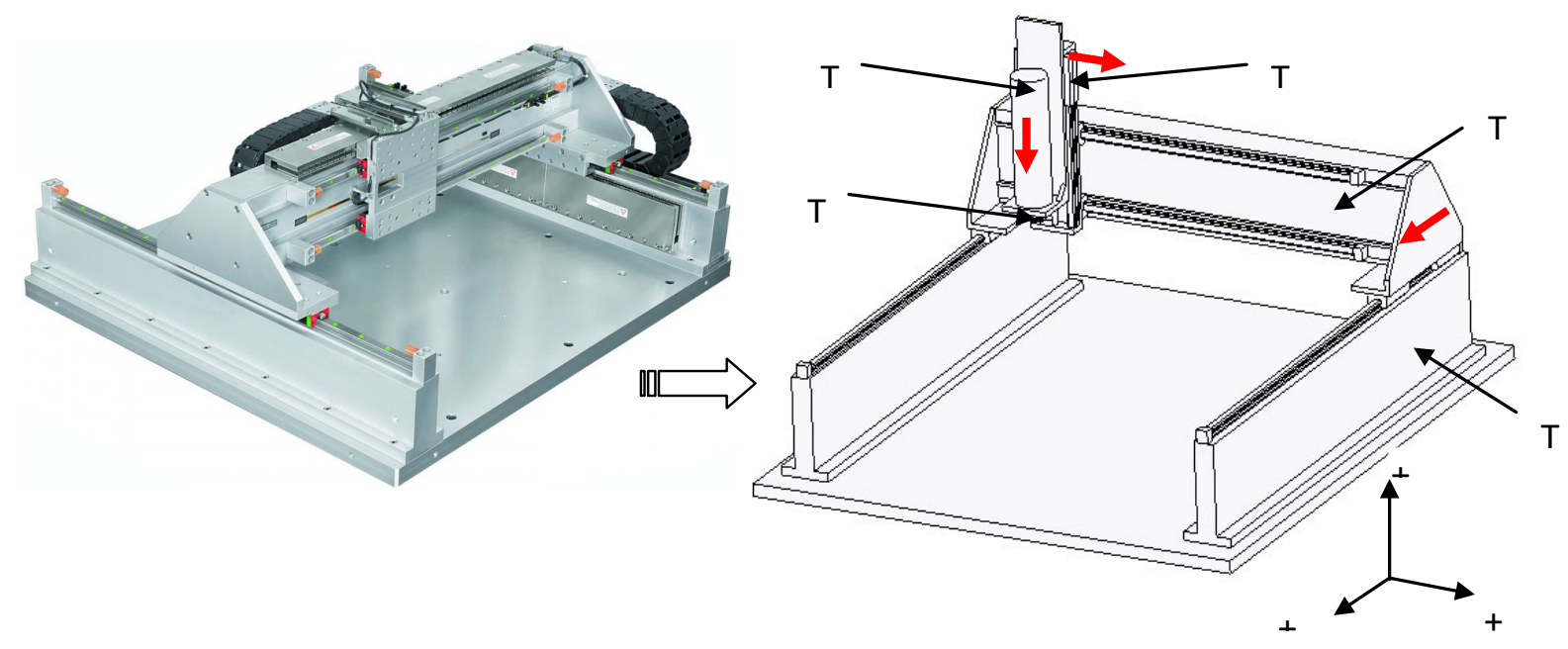

Fig. 1. Simplified model of a 3-axial machining center LMG2A-CB6-CC8 [4] 


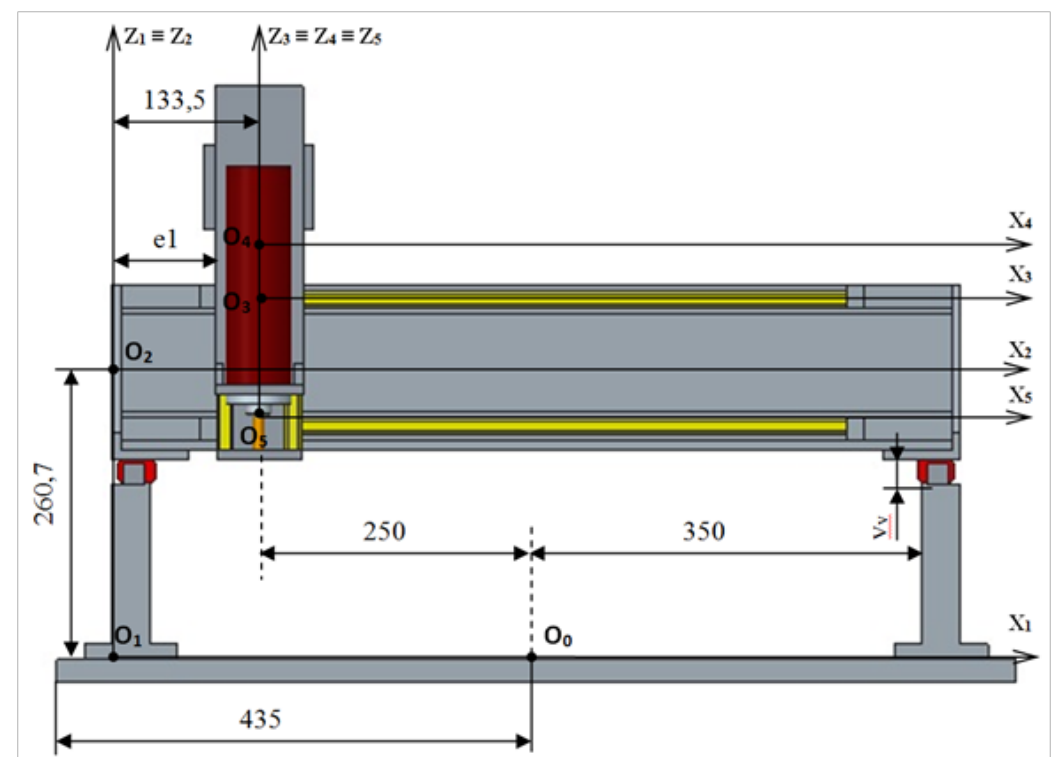

Fig. 2. Detailed calculation model of a 3-axial machining center - a sketch

machine by Hiwin (Fig. 1). The foundation of the machine features linear axial drives for $\mathrm{X}$ and $\mathrm{Y}$ [4]. The axis $\mathrm{Z}$ is driven by a combination of a stepper engine and a ball screw.

\section{DIGITAL MODEL OF THE MACHINING CENTER AND AN IDEAL WORKPIECE}

The machining center basic dimensions are established and the systems of coordinates of individual model bodies are visualized in a calculation model sketched in Fig. 2.

\section{Model bodies of the machining center}

Rotary motion transformational matrices have been established for model bodies $\mathrm{T}_{1}$ to $\mathrm{T}_{5}$ as have the transformational vectors of straight line motions and the vectors of initial position with respect to the next body. E.g. the model body $\mathrm{T}_{1}$, representing the bed (Fig. 3), does not carry on any motion with respect to the immotile workpiece $\mathrm{T}_{0}$. The workpiece is fixed in the $\mathrm{X}_{1} \mathrm{Y}_{1}$ plane in a way that its lower plane and the plane of the bed align identically. Structural dimensions of the bed model are listed in Table 1.

Therefore, the following holds for the transformational matrix of the rotary motion:

$$
\left[\mathbf{R}_{10}\right]=\left[\mathbf{R}_{10}(t)\right]=[\mathbf{E}]
$$

Transformational vector of the straight line motion will be:

$$
\left\{\mathbf{T}_{10}\right\}=\left\{\mathbf{T}_{10}(t)\right\}=\{0\}
$$

The vector of the initial position looks like this:

$$
\begin{gathered}
\left\{\mathbf{K}_{10}\right\}=\left\{-\left(e 1+h / 2+B_{\text {omax }} / 2\right)-\right. \\
\left.-\left(d 1 / 2+v_{v}+g 1+j 4+j 5+j 1\right) 0\right\}^{\mathrm{T}}
\end{gathered}
$$

where the values of the individual design dimensions are as follows: $\mathrm{d} 1=65 \mathrm{~mm}, \mathrm{e} 1=95 \mathrm{~mm}$, $\mathrm{g} 1=40 \mathrm{~mm}, \mathrm{~h}=77 \mathrm{~mm}, \mathrm{j} 1=10.7 \mathrm{~mm}$. The $\mathrm{v}_{\mathrm{v}}$ dimension represents the height clearance of the lead determined by the machine's design $(22.7 \mathrm{~mm})$ and the $\mathrm{B}_{\text {omax }}$ dimension is the maximum width of the workpiece the tool is capable of machining.

\section{Ideal workpiece virtual tool machining}

We contemplate virtual milling of a cabinetshaped workpiece made of common structural steel with higher carbon content marked 12050 (pursuant to the STS) [4] and the following dimensions $\mathrm{Lo}=500 \mathrm{~mm}, \mathrm{Bo}=\mathrm{Bo}_{\max }=500 \mathrm{~mm}$,

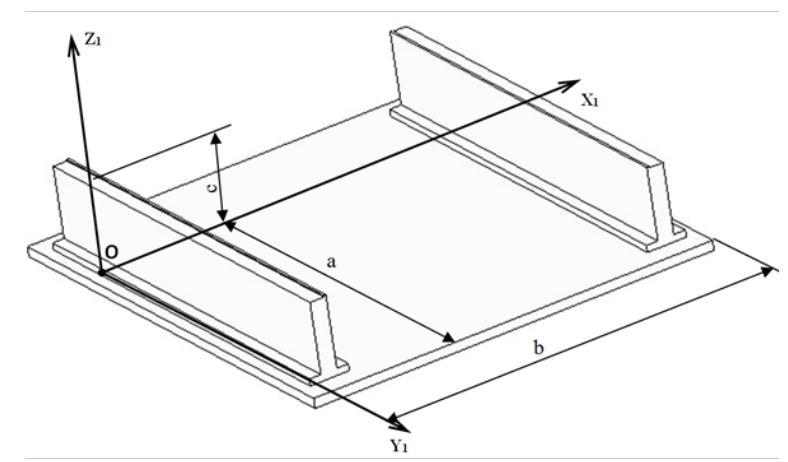

Fig. 3. Detailed calculation model of the bed 
$\mathrm{Ho}=\mathrm{Ho}_{\max }=150 \mathrm{~mm}$. The lower plane of the workpiece and the upper plane of the table are levels and the position of the workpiece on the table is symmetrical [13].

Let us contemplate horizontal milling (parallel and contra-rotating) of the plane area of the workpiece with the face of the tool. The tool is a TK 202992 HPC burr cutter with a diameter of $d_{f}=10 \mathrm{~mm}$ and the number of teeth $z_{f}=4$, which is shown at Fig. 4 [5].

Cutting conditions:

- depth $h_{f}$ and width $d / 2$ of milling $-5 \mathrm{~mm}$,

- machining by moving transom $f_{y}$ and support $f_{x}-($ direction of the axis $Y$ and $X)$,

- the shift towards the cutter tooth $f_{(x, y, z)}-0.045$ $\mathrm{mm}$,

- cutting speed $v_{c}-180 \mathrm{~m} \cdot \mathrm{min}^{-1}$,

- for the length of $500 \mathrm{~mm}$ the $t_{(s)}$ is $=29.09 \mathrm{~s}$.

If we look at the layout of the machine with the workpiece, we are machining the upper part of the workpiece, i.e. we are slashing the upper edge. We take both, the parallel and the contra-rotating milling into account. We will carry out the inaccuracy analysis every time the tool shifts by the value " $k$ ", which we have arbitrarily defined as $50 \mathrm{~mm}$, in the direction of the individual node sequence as shown in the figure (Fig. 5).

Upon adjustments, the individual transformational vectors $\left\{\mathbf{K}_{\mathrm{i}+1, \mathrm{i}}\right\}$ and $\left\{\mathbf{T}_{\mathrm{i}+1, \mathrm{i}}(t)\right\}$ and transformational matrices of rotary motions $\left[\mathbf{R}_{\mathrm{i}+1, \mathrm{i}}(t)\right]$ can be identified.

Transformational matrices of rotary motions:

$$
\left[\mathbf{R}_{54}(t)\right]=\left[\mathbf{R}_{43}(t)\right]=\left[\mathbf{R}_{32}(t)\right]=\left[\mathbf{R}_{21}(t)\right]=\left[\mathbf{R}_{10}(t)\right]=[\mathbf{E}]
$$

Transformational vectors:

$$
\begin{gathered}
\left\{\mathbf{T}_{54}(t)\right\}=\left\{\mathbf{T}_{43}(t)\right\}=\left\{\mathbf{T}_{32}(t)\right\}=\left\{\mathbf{T}_{10}(t)\right\}=\{0\} \\
\left\{\mathbf{T}_{21}(t)\right\}=\left\{0+w_{2}(t) 0\right\}^{\mathrm{T}}=\left\{0+\frac{f y \cdot z f \cdot n v \cdot t(s)}{60} 0\right\}^{\mathrm{T}} \\
\left\{\mathbf{K}_{54}\right\}=\{00-o\}^{\mathrm{T}} \\
\left\{\mathbf{K}_{43}\right\}=\left\{0 g 1+j 1+j 2+j-i / 2-(m 3-m)+H_{\text {omax }}\right\}^{\mathrm{T}} \\
\left\{\mathbf{K}_{32}\right\}=\left\{e l+h / 2 d 1 / 2+v_{v} f / 2-i 1\right\}^{\mathrm{T}} \\
\left\{\mathbf{K}_{21}\right\}=\left\{00 f / 2+v_{v}+c\right\}^{\mathrm{T}} \\
\left\{\mathbf{K}_{10}\right\}=\left\{-\left(e l+h / 2+B_{o} / 2\right)-\left(d 1 / 2+v_{v}+g 1+j 1+j 2+j\right) 0\right\}^{\mathrm{T}}
\end{gathered}
$$

Position vector $\left\{\mathbf{r}_{\mathrm{n}}\right\}_{\mathrm{y}}$ of the tool's functional point in the coordinate system of the $T_{5}$ spindle will be:

$$
\left\{\mathbf{r}_{\mathrm{n}}\right\}_{\mathrm{y}}=\left\{\boldsymbol{r}_{5}\right\}_{\mathrm{y}}=\left\{d / 20-v_{n}\right\}^{\mathrm{T}}
$$

Upon entering numerical values of individual structural dimensions, the numerical representation of the respective vectors will be obtained. 
Table 2. Virtual machining parameters in the positive direction of the $Y$-axis

\begin{tabular}{|c|c|c|c|c|c|c|c|c|c|c|c|}
\hline Position & 0. & 1. & 2. & 3. & 4. & 5. & 6. & 7. & 8. & 9. & 10. \\
\hline $\begin{array}{c}\text { Revolutions } \\
(\mathrm{rpm})\end{array}$ & 1 & 277.8 & 555.6 & 833.4 & 1111.2 & 1389 & 1666.8 & 1944.6 & 2222.4 & 2500.2 & 2778 \\
\hline Time (s) & 0 & 2.909 & 5.818 & 8.727 & 11.63 & 14.54 & 17.45 & 20.36 & 23.27 & 26.18 & 29.09 \\
\hline $\begin{array}{c}\text { Coordinate Y } \\
(\mathrm{mm})\end{array}$ & 0 & 50 & 100 & 150 & 200 & 250 & 300 & 350 & 400 & 450 & 500 \\
\hline
\end{tabular}

Finally, when we have entered the respective numerical values, we obtain particular position vectors of the tool's contact point expressed in the following form:

$$
\begin{aligned}
& \left\{\mathbf{r}_{4}(t)\right\}_{\mathrm{y}}=\left\{\begin{array}{lll}
5 & 0 & -185.8
\end{array}\right\} \\
& \left\{\mathbf{r}_{3}(t)\right\}_{\mathrm{y}}=\left\{\begin{array}{ll}
5 & 86.7-184.7
\end{array}\right\} \\
& \left\{\mathbf{r}_{2}(t)\right\}_{\mathrm{y}}=\{138.5141 .9-115.7\} \\
& \left\{\mathbf{r}_{1}(t)\right\}_{\mathrm{y}}=\left\{138.5141 .9+17.19_{\mathrm{t}(\mathrm{s})} 145\right\} \\
& \left\{\mathbf{r}_{0}(t)\right\}_{\mathrm{y}}=\left\{-2450+17.19 t_{(\mathrm{s})} 145\right\}
\end{aligned}
$$

The matrix equation (17) expresses a set of three parametric formulas representing a straight line, where the parameter is time $t$. Upon moving in direction of the axis $Y$, the tool (a burr cutter) creates two plane surfaces plotted for the workpiece as $X_{0}=-245 \mathrm{~mm}$ and $Z_{0}=145 \mathrm{~mm}$ by means of its circumferential and frontal cylindrical area. Initial position of the tool's contact point according to $\mathrm{v}$ at the time $t$ $=0 \mathrm{~s}$ will be plotted as $\{-2450145\}$ and the final position of the same point at the time $t=29.09 \mathrm{~s}$ will be plotted as $\{-245500145\}$ (Table 2).

We will proceed with the virtual machining in the positive direction of the axis $X$, in the same manner, we applied to virtual machining in the positive direction of the axis $Y$. Since it is necessary to assume the initial position of virtual machining, we will proceed further in the negative direction of the axis $Y$. Then we will finalize the virtual machining in the negative direction of the axis $X$.

It is not necessary to simulate numerically the entire model subject to virtual machining, rather, it is sufficient to perform the analysis of numerical simulation in the designated points. We draw on our position that the machining starts in coordinates defining the tool's contact point with the workpiece as per (17). The course run by the transom together with the support, the slide, the headstock and the spindle over time $\mathrm{t}$, will be $2000 \mathrm{~mm}$. The entire process of virtual machining with the parameters stipulated above is scheduled to last $\mathrm{t} \approx 116.346 \mathrm{~s}$ and the time of machining a single segment $\mathrm{k}=50 \mathrm{~mm}$ will be $\Delta \mathrm{t} \approx 2.909 \mathrm{~s}[1]$.

\section{CALCULATION OF DEFORMITIES TO MODEL BODIES}

In the course of virtual machining of the selected semi-product, the effects of force in individual headstock positions will be simulated by an equation for tangential component of the cutting force as per [6].

$$
F_{c}=824 \cdot h_{f}^{0,95} \cdot b_{f}^{1,1} \cdot z_{f} \cdot f_{x, y}^{0,8} \cdot d_{f}^{-1,1}(\mathrm{~N})
$$

where individual exponents characterize the effect the respective value has on the median of the $F_{c}$ component yielded by experiments. Other dimensions are entered in $\mathrm{mm}[6,15]$.

Upon completing the equation (18) with numerical values, we obtain:

$$
F_{c}=824 \cdot 5^{0,95} \cdot 5^{1,1} \cdot 4 \cdot 0.045^{0,8} \cdot 10^{-1,1}=593.5 \mathrm{~N}
$$

\section{Symmetrical co-milling - frontal}

The purpose of the tool's rotation is identical with the shift of the workpiece, i.e. the transom moves in direction of the tool's rotation [11]. 


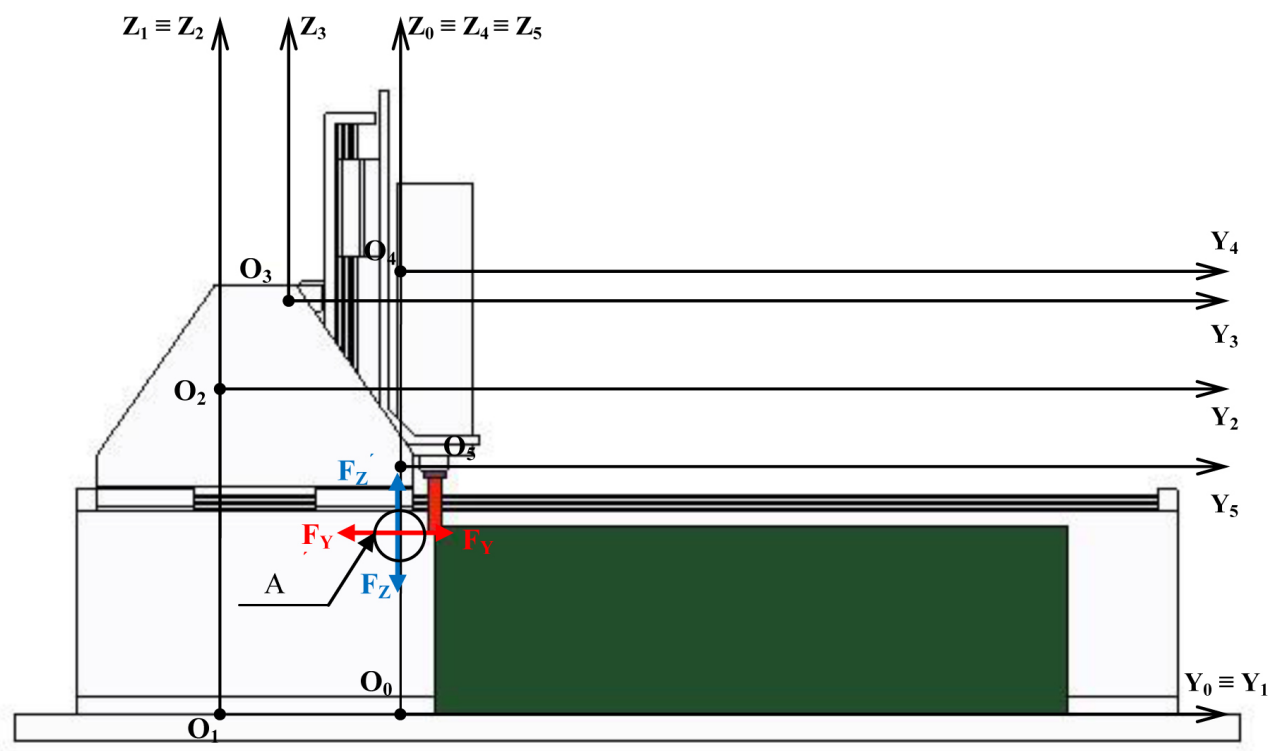

Fig. 6. Virtual machining analysis of co-milling
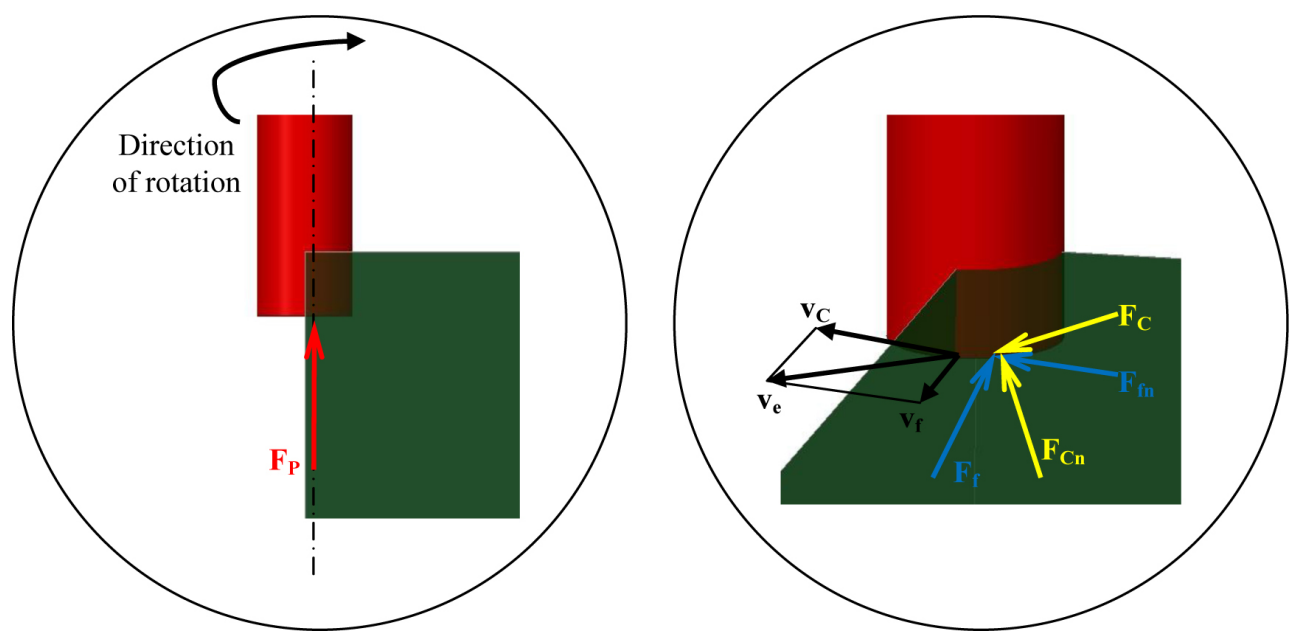

Fig. 7. Distribution of forces, motions and velocities in co-milling - detail A

By the identified median value of the $F_{c}(18)$ component, the cutting forces in individual directions of the coordinate axes were established $[10,17]$ for symmetrical co-milling (Fig. 6).

Cutting forces and velocities take effect in the direction shown in the figure (Fig. 7).

Having considered the structure of the machine and that of the individual model bodies, we will be taking into account deformities to the transom, the support, the slide and the headstock together with that to the spindle. The FEM simulation will make use of the most adverse values.

In direction of the $Y$ axis:

$$
\begin{gathered}
F_{X}=0.4 \cdot F_{c}=0.4 \cdot 593.5=237.4 \mathrm{~N} \\
F_{Y}=0.95 \cdot F_{c}=0.95 \cdot 593.5=563.8 \mathrm{~N} \\
F_{Z}=0.55 \cdot F_{c}=0.55 \cdot 593.5=326.4 \mathrm{~N}
\end{gathered}
$$

In direction of the $X$ axis:

$$
\begin{gathered}
F_{X}=0.95 \cdot F_{c}=0.95 \cdot 593.5=563.8 \mathrm{~N} \\
F_{Y}=0.4 \cdot F_{c}=0.4 \cdot 593.5=237.4 \mathrm{~N} \\
F_{Z}=0.55 \cdot F_{c}=0.55 \cdot 593.5=326.4 \mathrm{~N}
\end{gathered}
$$

The pros of co-milling is lesser roughness of the machined surface, greater durability of the tool, lesser cutting output required and other [13].

\section{Symmetrical contra-rotating milling - frontal}

The purpose of the tool rotation is contrary to the shift of the workpiece (the shift of the transom in our case). Anotherwords, the transom moves in direction counter the direction of the tool rotation [13]. From the identified median value of the $F_{c}$ (18) component, the cutting forces in individual 
directions of the coordinate axes have been established [10] for the symmetrical contra-rotating milling:

In direction of the $Y$ axis:

$$
\begin{aligned}
& F_{X}=0.85 \cdot F_{c}=0.85 \cdot 593.5=504.4 \mathrm{~N} \\
& F_{Y}=0.65 \cdot F_{c}=0.65 \cdot 593.5=385.7 \mathrm{~N} \\
& F_{Z}=0.55 \cdot F_{c}=0.55 \cdot 593.5=326.4 \mathrm{~N}
\end{aligned}
$$

In direction of the $X$ axis:

$$
\begin{aligned}
& F_{X}=0.65 \cdot F_{c}=0.65 \cdot 593.5=385.7 \mathrm{~N} \\
& F_{Y}=0.85 \cdot F_{c}=0.85 \cdot 593.5=504.4 \mathrm{~N} \\
& F_{Z}=0.55 \cdot F_{c}=0.55 \cdot 593.5=326.4 \mathrm{~N}
\end{aligned}
$$

The pros of the contra-rotating milling is smoother pull of the teeth and more favorable mechanical strain. The cons are increased wear and tear of the tool, greater roughness of the machined surface, subsliding of the machined material etc. [13].

The body of knowledge collected over many years and supported by practical experiments allows for making an assumption that the final precision of the machine will be better achieved in co-milling, or rather that the final inaccuracy will be lesser in parallel than in the contra-rotating milling.

\section{DIGITAL MODEL OF A REAL WORKPIECE}

The virtual model was subjected to the FEA analysis, utilizing a PTC Creo software. For the purpose of the analysis, the body subjected to calculations was divided into many independent component parts (final components). The final component analysis module in PTC Creo supports calculations of pressures, strains, safety factors and can also establish natural frequencies. Before that, material and support specifications need to be selected. The load and pressures can be entered directly into the Creo software $[7,14]$.

Our model of the selected workpiece was subjected to 40 circumferential measurements. The results were analyzed in Microsoft Excel.

Individual results are represented in graphs in Fig. 8 and 9 respectively, showing the inaccuracy courses on particular axes at the set milling directions, separately for parallel and contra-rotating milling. Below each graph, color-coded differences are accounted for between the real (orange) and the ideal (blue) machined surface.

Fig. 8 offers a picture of the inaccuracy course in the $X$ direction when the tool moves in the direction of the axis $\pm Y$, which makes it apparent, that
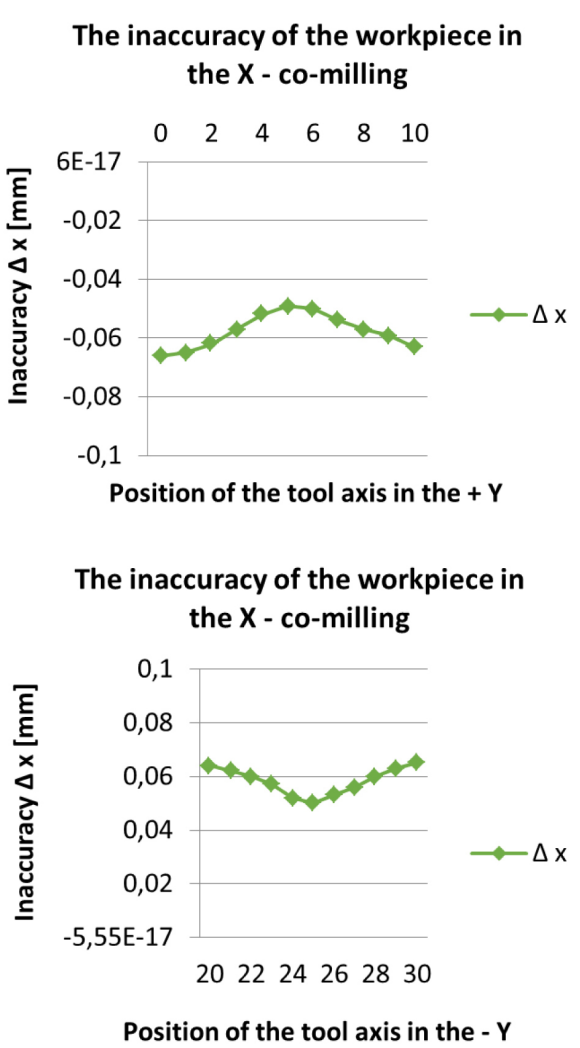

Fig. 8. Graphic representation of the inaccuracy in the $\mathrm{X}$ direction when the tool moves in the $\pm \mathrm{Y}$ direction

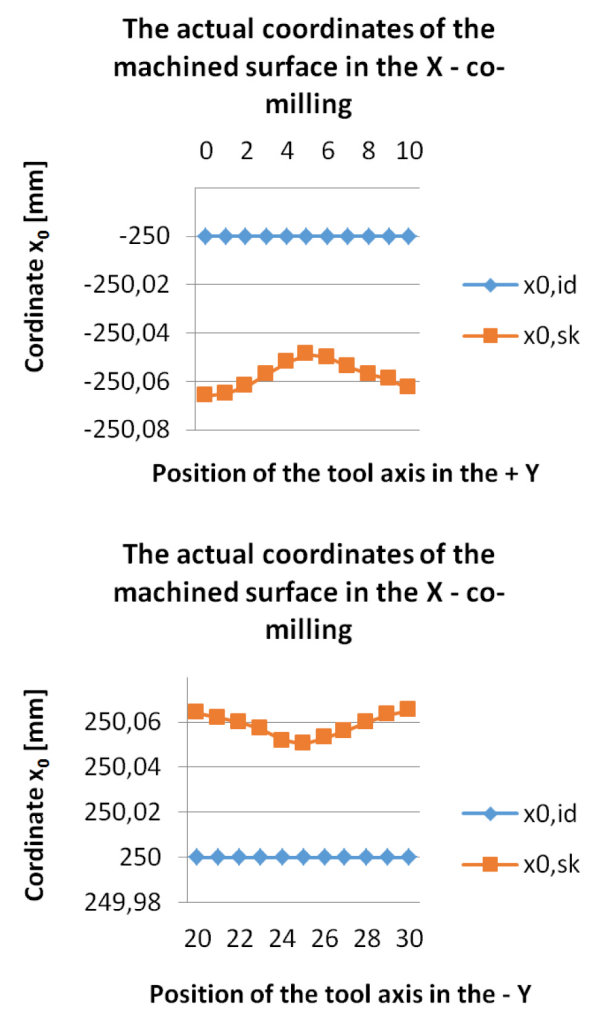

Fig. 9. Real coordinates of the machined surface in the $\mathrm{X}$ direction when the tool moves in the $\pm \mathrm{Y}$ direction 
the inaccuracy is slightly receding in one area. This phenomenon is caused by the transom's position in the center of the bed, where the forces emergent in the technological process are distributed more favorably towards the portal than they are in limit positions. The greatest inaccuracy has been found in positions $0,10,20$ and 30 , when the transom, the support, the slide with the headstock and the spindle are located in limit positions, where the distribution of forces is less than ideal. The real and the ideal coordinates of the machined surface in the $X$ direction when the tool moves in the direction of the axis $\pm Y$ are shown in Figure 9.

\section{CONCLUSION}

From the presented facts it follows that if increased precision is needed, the milling machine has to undergo some structural adjustments, especially in the machining directions $\mathrm{Y}$ and $\mathrm{Z}$. The greatest inaccuracies in those directions were inaccuracies found in direction $\mathrm{Z}=0.636 \mathrm{~mm}$ and in direction, $Y=0.879 \mathrm{~mm}$ in co-milling. In contra-rotational milling, the inaccuracy found in the axis $Z=0.666 \mathrm{~mm}$ and in the axis $Y=1.379 \mathrm{~mm}$. The final inaccuracies found in the $X$ direction were rather good, at $X=0.066 \mathrm{~mm}$ in co-milling and $\mathrm{X}=0.130 \mathrm{~mm}$ in contra-rotational milling.

Thus it is our conclusion the final precision of the machine appears to be in co-milling rather than in contra-rotational milling, or that the final inaccuracy is lesser in the parallel than in the contra-rotational milling.

\section{Acknowledgments}

The article was drawn up with the support of the projects: VEGA 1/0124/15 Research and development of advanced methods for virtual prototyping of production machines, APVV-15-0149 Research of new measuring methods of machine condition and KEGA 039TUKE-4/2016 Creation of virtual laboratories based on WEB technologies supporting educational process in the field of Manufacturing Technology.

\section{REFERENCES}

1. Demeč P., Svetlík J., Semjon J. Virtual prototyping machine tools in terms of the dynamics of the machining process. SjF TU, 2011.

2. Demeč P. Manufacturing Technology - basics of the construction. TU, 2013.
3. Moskal' D. Audit of the accuracy of machine tools. Transfer inovácií, 1999.

4. Hiwin Motion control \& Systems. Hiwin, 2016.

5. Hoffmann group Tools to make you better. Hoffman group, 2016.

6. Beňo J. Theory of metal cutting. SjF TU, 1999.

7. Keka B. Finite Element Analysis is integrated into CAD systems. MM Spectrum, 2005/6, 48.

8. Korba P., Pil'a J. Application of CAx systems when designing the construction of nodes of a helicopter. Zakład Poligraficzny WISŁA, 2013.

9. Korba P., Pil'a J., Sabo J., Antoško M. The use of CAX systems as a tool to reduce the economic costs in the aviation industry. SGEM 2014, Sofia, Bulgaria 2014, 385-392.

10.Žilinský, A., Svetlík, J., Drabiková, E.: New CAD softwares in engineering, 2014. In: Transfer inovácií. Č. 30, s. 137-140. - ISSN 1337-7094.

11. Baron P. Research and application of methods of technical diagnostics for the verification of the design node. Measurement, Vol. 94, 2016, 245-253.

12. Jurko J. Study on cone roller bearing surface roughness improvement and the effect of surface roughness on tapered roller bearing service life. International Journal of Advanced Manufacturing Technology, Vol. 82, 2016, 1099-1106.

13. Kniebugl L. Engineering Technology. Mechossi, 2008.

14. Stanova E. Fedorko G. Kmet S. Molnár V. Fabian M. Finite element analysis of spiral strands with different shapes subjected to axial loads. Adv. Eng. Softw., 2015.

15. Gajdoš I. Slota J. Spišák E. Jachowicz T. TorŚwiątek A. Structure and tensile properties evaluation of samples produced by Fused Deposition Modeling. Open Engineering, 2016, 1, 6, 86-89.

16. Debski H. Koszalka G. Ferdynus M. Application of fem in the analysis of the structure of a trailer supporting frame with variable operation parameters. Eksploatacja i Niezawodnosc. Maintenance and Reliability, 2012, 107-113.

17. Michalik P. Zajac J. Hatala M. Mital D. Fecova V. Monitoring surface roughness of thin-walled components from steel C45 machining down and up milling. Measurement, 2014, 416-428.

18. Palenčár R. Ďuriš S. Dovica M. Palenčár J. Application of Monte Carlo method for evaluation of uncertainties of temperature measurement by SPRT. IMEKO 21 World Congress. - Prague, Czech 2016, 1-6.

19. Zegzulka J. Jezerska L. Liptakova T. Hlosta J. Necas J., study of structural and selected mechanical/ physical properties of metal powders. Met. 2015 24TH Int. Conf. Metall. Ostrava, Czech 2015, 1457-1462. 